\title{
The Predictive Value of Personality Traits for Psychological Problems (Stress, Anxiety and Depression): Results from a Large Population Based Study
}

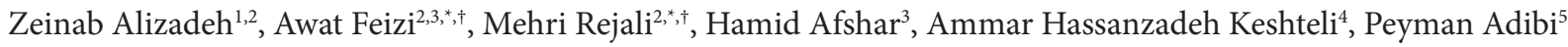 \\ ${ }^{1}$ Department of Public Health, Faculty of Health, Torbat Heydariyeh University of Medical Sciences, Torbat Heydariyeh, Iran \\ ${ }^{2}$ Department of Biostatistics and Epidemiology, School of Health, Isfahan University of Medical Sciences, Isfahan, Iran \\ ${ }^{3}$ Psychosomatic Research Center, Isfahan University of Medical Sciences, Isfahan, Iran \\ ${ }^{4}$ Department of Medicine, University of Alberta, Edmonton, Alberta, Canada \\ ${ }^{5}$ Department of Internal Medicine, School of Medicine and Integrative Functional, Gastroenterology Research Center, Isfahan University of Medical Sciences, Isfahan, Iran
}

\section{ARTICLE INFO}

\section{Article History}

Received 19 December 2016

Accepted 11 November 2017

Keywords

Personality traits

stress

anxiety

depression

ROC analysis

\begin{abstract}
The current study aimed to determine the prognostic values of personality traits for common psychological problems in a large sample of Iranian adult. In a large sample of healthy people $(n=4763)$ who lived in Isfahan province; the NEO-FFI was used to assess the personality traits; depression and anxiety were assessed using the "Hospital Anxiety and Depression Scale (HADS)" also stress was measured through Persian validated version of General Health Questionnaire (GHQ-12). Receiver Operating Characteristics Curve (ROC) analysis was used as main statistical method for data analysis. ROC analysis showed neuroticism was the best predictor for all psychological problems with highest area under the curve (AUC) (95\% confidence interval) for stress, $0.837(0.837-0.851)$, anxiety $0.861(0.847-0.876)$ and depression $0.833(0.820-0.846)(\mathrm{p}<.001)$ and the corresponding cut-off points (sensitivity, specificity), were 21.5 (77\%, 66\%), $22.5(81 \%, 77 \%)$ and 20.5 (77\%, 74\%), respectively. Other personality traits were significant protective factors for being affected with psychological problems $(\mathrm{p}<.001)$. Similar findings were observed separately in women and men. The present study showed that the neuroticism is significant risk factor for being affected with three psychological problems while other traits are significant protective factors. Personality traits are useful indices for screening psychological problems and an effective pathway toward prevention in general population.
\end{abstract}

(C) 2018 Atlantis Press International B.V.

This is an open access article under the CC BY-NC license (http://creativecommons.org/licences/by-nc/4.0/).

\section{INTRODUCTION}

A psychological disorder is a clinically significant syndrome or behavioral psychological pattern that is associated with an increased risk of pain, death, suffering and disability [1]. Such common and serious disorders occur worldwide [2] and approximately half of Americans and nearly 40 per cent of Europeans have criteria for psychological disorders in their lifetime [3,4], moreover, the prevalence of such disorders in Iran have been reported between $10 \%$ and $20 \%$ [5]. Psychological disorders are also one of five causes of living with a disability and they are gradually moving to higher levels of the major causes of morbidity in populations [6]. Research studies have shown that depression, anxiety, and stress as the most common Psychological disorders in general populations that have emerged as a public health priority because they lead to reduced quality of life at individual level and have negative impacts on health, performance, and efficiency. Since such disorders have chronic intermittent periods, they impose a heavy disease burden during lifetime [4,6-8]. Epidemiological studies have also revealed

\footnotetext{
*Corresponding authors.Emails: awat_feiz@hlth.mui.ac.ir; rejali_m@yahoo.com

${ }^{\dagger}$ Co-corresponding author with equal contribution.
}

that Psychological problems are strong predictors for mortality from heart disease, stroke, and cancer [9].

Furthermore, individual differences in personality traits have been reported as one of the important factors contributing to explain why only some people are experiencing mental trauma [10]. The hypothesis for the relationship between personality and mental health was proposed since the Ancient times in Greece and the best and the most well-known theories have been attributed to Hippocrates and Galen. various studies have indicated that common Psychological disorders can be strongly predicted by the presence of a personality trait [11] and the issue has been investigated in a number of models [12].

In this respect, the Five-Factor Model (FFM) is the most recently accepted normal personality model. This model draws five personality dimensions including neuroticism, extraversion, openness, agreeableness, and conscientiousness for an individual [7]. A meta-analysis of 175 cross-sectional studies showed that all groups of Psychological disorders received high scores in the personality dimensions of neuroticism; on the other hand, lower extroversion scores were obtained [11]. Personality modes are considered as predictive factors for being affected with depression 
and anxiety. Several studies in this field have also indicated conflicting results associated with neuroticism. A review on personality pathology and depression showed that high neuroticism scores were a poor predictor of depression [13]. Besides, some studies demonstrated that high extraversion was supposed to have a protective effect on depression [7]. Personality dimensions of neuroticism and extraversion were also taken into account as predictive factors for stress [14]. Costa and McCrae believed that neuroticism or negative emotionality was an important trait in personality evaluation and individuals who scored high on this trait were more likely to get through psychological disorders and various problems such as anxiety, fear, depression, irritability, and physical symptoms [15].

Determining the relationship between personality modes and Psychological problems is of utmost importance because it sheds light on the concepts of psychopathology and helps in identifying individuals at risk as well as their early treatment [16].

The studies conducted so far have been mostly focused on the relationship between two dimensions of neuroticism and extraversion and catching up with psychological problems in specific populations. In addition, no studies have been conducted up to now to determine the prognostic scores of being affected with psychological problems based on personality traits worldwide. Therefore, the aim of present study was to determine the predictive values of five personality factors for being affected with common psychological problems (depression, anxiety, and stress) in a total population as well as in categories of age and gender in a large sample of Iranian general adults.

\section{METHODS}

\subsection{Study Design and Participants}

We extracted our data from the framework of the Study on the Epidemiology of Psychological, Alimentary Health and Nutrition (SEPAHAN), describing the epidemiological concepts of functional gastrointestinal disorders and their association with lifestyle and psychological factors on 2010. Detailed information about this survey has already been published [17].

The studied population was selected among 4 million people in 20 counties across Isfahan province. Multistage random cluster sampling was performed by geographical regions to determine the number of participants needed in each of region. The participants were selected from healthy people who live in Isfahan province. The questionnaires were given to the participants in their home and workplace and they answered to the questionnaires in their resting time. All data was collected anonymous and confidential. Participating to this study was completely optional. The response rate was $86.16 \%$. In this study, we used the data of 4763 adults who had completed information on demographic data, personality traits, stressful life events, coping with stress, social support, and psychological problems such as depression, anxiety and stress. The protocol of study was approved by the ethics committee of Isfahan University of Medical Sciences (IUMS), and was clarified for all the participants, and a written informed consent was obtained from all participants.

\subsection{Study Instruments and Variables Assessment}

To measure personality traits we used NEO Five Factor Inventory. The NEO-FFI is a 60 self-report item version of the 240 item Revised NEO Personality Inventory (NEO-PI-R) and measures five personality domains: Neuroticism, Extraversion, Openness to experience, Agreeableness, and Conscientiousness [18]. To permit the examination of each personality domain's specific elements, item cluster subcomponents have been developed and cross-validated. Each domain is measured by 12 items. The answer format is a 5-point Likert-type scale (0-4), ranging from "Strongly disagree" (0) to "Strongly agree" (4). Scores are summed totals (after reversing negatively keyed items) and have a range of 0-48 for each of the five personality domains. A total of 28 NEO FFI items are reverse-worded. The translation and back-translation method was used to make the Persian translation of NEO-FFI valid also in Iranian population, Cronbach's alpha is shown for neuroticism, extraversion, openness, agreeableness and conscientiousness as $0.76,0.65,0.59,0.48$ and 0.75 , respectively [19].

To measure depression and anxiety we used The Hospital Anxiety and Depression Scale (HADS). It is a brief and widely used instrument to measure psychological stress in cancer patients and a recent review of the literature on the validity of the HADS clearly indicates that it is a well-performed questionnaire in assessing the symptom severity and case-ness of anxiety disorders and depression in primary care patients and even in the general population. The HADS contains 14 items and consists of two subscales: anxiety and depression. Each item is rated on a four-point scale, giving maximum scores of 21 for anxiety and depression. Scores of 11 or more on either subscale are considered to be a significant 'case' of psychological morbidity, while scores of 8-10 represents 'borderline' and 0-7 'normal'. We used Persian validated version of HADS with $(\alpha=0.78)$ for anxiety and $(\alpha=0.86)$ for depression [20].

Stress were measured through Persian validated version of General Health Questionnaire (GHQ-12) $(\alpha=0.87)$. It is a 12 -item questionnaire that assesses psychological stress. The scale asks whether there respondent has experienced a particular symptom or behavior recently. Each item is rated on a four-point scale (less than usual, no more than usual, rather more than usual, or much more than usual), with the 0-0-1-1 method yielding in scores between 0 and 12 [21].

\subsubsection{Assessment of other variables}

Data about age (year), sex (male/female), marital status (single, married, divorced or widowed) educational level (less than diploma (less than 12 year formal education), diploma, university education), BMI (weight $(\mathrm{kg}) /$ height $\left(\mathrm{m}^{2}\right)$ ), smoking (current smoker, ex-smoker, non-smoker) and physical activity (hour per week) suffering from functional gastrointestinal disorders (FGIDs) and chronic disease (diabetes, cancer, respiratory, hypertension, cardiovascular) and various anti-psychotic medicines use were collected. 


\subsection{Statistical Analysis}

Data were analyzed by SPSS version 15.0 (SPSS Inc, Chicago, Illinois, USA). P-value <.05 was considered statistically significant. Continuous variables were expressed as mean $\pm \mathrm{SD}$ and qualitative data as frequency (percentage). Multivariate analysis of variance was used for comparing the scores of personality traits between groups. Chi-square test was used for comparing the prevalence of psychological disorders between studied groups. ROC analysis was conducted for evaluating the diagnostic value of personality traits scores. The optimal each personality trait score was defined as the values that maximized the distance to the identity (diagonal) line in ROC. Area under the curve (AUC) and its 95\% confidence interval was calculated for each personality trait score. Also, to evaluate the performance of identified cutoff value the relevant sensitivity and specificity was calculated. Finally, logistic regression model was performed for identifying the prognostic values of all personality traits' scores in univariate and multivariable settings. All statistical analysis was conducted using SPSS software version15 (SPSS Inc. Chicago, Illinois USA).

\section{RESULTS}

Of the 4763 participants in this study, 2106 individuals (44.2\%) were men and 2657 people (55.8\%) were women. 2874 participants $(60.3 \%)$ were below or equal to 40 years old and $1889(39.7 \%)$ aged over 40 years.

Table 1 illustrates the prevalence of Psychological problems in total population and in age and gender groups. The prevalence of the three Psychological problems in women was significantly higher than men. The odds ratios of being affected with stress, anxiety, and depression among women compared with men were $\mathrm{OR}=1.66, \mathrm{OR}$ $=1.87$, and $\mathrm{OR}=1.79(\mathrm{p}<.001)$; respectively. Moreover, the prevalence of stress and anxiety in individuals below 40 years of age was also significantly lower than the other group and odds ratios stress and anxiety were $\mathrm{OR}=0.81$, and $\mathrm{OR}=0.79(\mathrm{p}<.05)$; however, this relationship was not significant in the case of depression.
The results of multivariate analysis of variance (MANOVA) showed that the mean scores of personality traits among affected individuals compared to unaffected participants were significantly different. The mean scores of neuroticism, for all three psychological problems in affected participants were higher than non-affected individuals. Considering other four personality traits, it was shown that the mean scores of these traits in individuals with Psychological problems were lower than that in the non-affected group (stress, Wilk's $\lambda=0.632, \mathrm{~F}=69.51, \mathrm{p}<.001$; anxiety, Wilk's $\lambda=0.779, \mathrm{~F}=$ 264.30, $\mathrm{p}<.001$; depression, Wilk's $\lambda=0.698, \mathrm{~F}=401.77, \mathrm{p}<.001$ ) (Table 2).

Table 2 also presents the mean and standard deviation scores of personality traits in gender and age's groups. It was concluded that the mean scores were significantly higher in women than men (except the mean scores of extraversion) and the mean scores of all personality traits in the group aged below 40 years were significantly higher than the group above 40 years old (except for mean scores of extraversion in which no significant difference was observed between both groups) (gender, Wilk's $\lambda=0.932, \mathrm{~F}=69.51$, $\mathrm{p}<.001$; Wilk's age, $\lambda=0.977, \mathrm{~F}=22.85, \mathrm{p}<.001)$.

To determine the prognosis of catching up with Psychological problems based on the personality traits, Receiver Operating Characteristic (ROC) curve was used. Table 3 shows the area under the curve (95\% confidence interval), the cut-off point, the specificity, and the sensitivity of the traits for each Psychological problem in the total population. The area under the curve for the personality trait of neuroticism was respectively $0.837,0.861$, and 0.833 for stress, anxiety and depression. The cut-off points (sensitivity, specificity) neuroticism, using the ROC curve; for predicting the risk of stress, anxiety, and depression were 21.5 (77\%, 66\%), 22.5 (81\%, $77 \%)$, and $20.5(77 \%, 74 \%)$. It was concluded that this personality traits is a significant risk factor for suffering from these psychological problems $(\mathrm{p}<.001)$. Higher scores of other personality traits were proper indicators for lack of studied Psychological problems $(\mathrm{p}<.001)$ (Fig. 1). The ROC curve analysis was also conducted to determine the predictive values of total score all personality traits

Table 1 Prevalence of psychological disorders in total population and in sex and age groups

\begin{tabular}{|c|c|c|c|c|c|c|c|}
\hline & & $\begin{array}{l}\text { Frequency (\%) } \\
\text { of stress }\end{array}$ & OR (95\% CI) & $\begin{array}{c}\text { Frequency (\%) } \\
\text { of anxiety }\end{array}$ & OR (95\% CI) & $\begin{array}{c}\text { Frequency (\%) } \\
\text { of depression }\end{array}$ & OR $(95 \% \mathrm{CI})$ \\
\hline \multicolumn{2}{|c|}{ Total population } & $1067(22.4)$ & & $654(13.7)$ & & $1338(28.1)$ & \\
\hline \multirow[t]{2}{*}{ Sex } & Men & $367(18.1)$ & $1.66(1.44-1.91)^{\star}$ & $204(10.0)$ & $1.87(1.57-2.24)^{*}$ & $454(22.2)$ & $1.79(1.57-2.04)^{*}$ \\
\hline & Women & $700(26.9)$ & & $450(17.2)$ & & $884(33.9)$ & \\
\hline \multirow[t]{2}{*}{ Age } & $\leq 40$ & $693(24.5)$ & $0.81(0.703-0.935)^{* *}$ & $429(15.1)$ & $0.79(0.668-0.945)^{\star \star}$ & $832(29.3)$ & $0.93(0.818-1.06)$ \\
\hline & $>40$ & $374(20.8)$ & & $225(12.4)$ & & $506(27.9)$ & \\
\hline
\end{tabular}

${ }^{\star} \mathrm{P}<.001 ;{ }^{*} \mathrm{P}<.05$.

Table 2 Means and standard deviations (SD) of personality traits in affected and non-affected people in total population and in gender and age groups

\begin{tabular}{|c|c|c|c|c|c|c|c|c|c|c|}
\hline \multirow{2}{*}{ Personality traits } & \multicolumn{2}{|c|}{ Stress } & \multicolumn{2}{|c|}{ Anxiety } & \multicolumn{2}{|c|}{ Depression } & \multicolumn{2}{|c|}{ Gender } & \multicolumn{2}{|c|}{ Age (year) } \\
\hline & Non-affected & Affected & Non-affected & Affected & Non-affected & Affected & Men & Women & $\leq 40$ years & $>40$ \\
\hline Neuroticism & $16.69(6.66)^{\star}$ & $26.03(6.96)^{*}$ & $17.43(6.92)$ & $27.72(6.60)^{*}$ & $16.30(6.57)$ & $25.27(6.70)^{\star}$ & $17.56(7.54)$ & $19.65(7.99)^{\star}$ & $19.28(8.01)$ & $17.89(7.57)^{\star}$ \\
\hline Extraversion & $30.71(6.18)^{\star}$ & $23.24(6.28)^{\star}$ & $30.04(6.40)$ & $24.52(6.43)^{*}$ & $30.94(6.10)$ & $25.13(6.25)^{*}$ & $29.88(7.18)$ & $28.35(6.93)^{\star}$ & $29.12(6.83)$ & $28.88(7.45)$ \\
\hline Openness & $24.41(4.85)^{*}$ & $23.57(5.30)^{*}$ & $24.32(4.86)$ & $23.81(5.04)^{* *}$ & + $24.54(4.83)$ & $23.54(4.94)^{*}$ & $23.67(5.31)$ & $24.33(5.24)^{\star}$ & $24.51(4.96)$ & $23.32(5.66)^{*}$ \\
\hline Agreeableness & $31.96(5.77)^{\star}$ & $28.97(5.96)^{*}$ & $31.77(5.71)$ & $28.45(5.88)^{*}$ & $32.20(5.62)$ & $29.11(5.78)^{*}$ & $30.26(6.51)$ & $31.67(6.19)^{\star}$ & $31.46(5.93)$ & $30.42(6.94)^{*}$ \\
\hline Conscientiousness & $37.41(6.37)^{\star}$ & $33.41(6.90)^{\star}$ & $36.99(6.41)$ & $33.94(6.96)^{*}$ & $37.51(6.22)$ & $34.23(6.83)^{*}$ & $36.03(7.55)$ & $36.44(6.95)^{\star *}$ & $36.51(6.64)$ & $35.87(8.02)^{\star *}$ \\
\hline
\end{tabular}


Table 3 Areas under the receiver operating characteristics curves (AUC) and their 95\% confidence interval (CI), sensitivity, specificity and cutoff point of personality traits for predicting psychological disorders in total population

\begin{tabular}{|c|c|c|c|c|c|c|c|c|c|c|c|c|}
\hline \multirow{2}{*}{$\begin{array}{l}\text { Personality } \\
\text { traits }\end{array}$} & \multicolumn{4}{|c|}{ Stress } & \multicolumn{4}{|c|}{ Anxiety } & \multicolumn{4}{|c|}{ Depression } \\
\hline & $\begin{array}{c}\text { AUC } \\
(95 \% \mathrm{CI})\end{array}$ & $\begin{array}{c}\text { Cut off } \\
\text { point }\end{array}$ & Sensitivity & Specificity & $\begin{array}{c}\text { AUC } \\
(95 \% \mathrm{CI})\end{array}$ & $\begin{array}{c}\text { Cut off } \\
\text { point }\end{array}$ & Sensitivity & Specificity & $\begin{array}{c}\text { AUC } \\
(95 \% \mathrm{CI})\end{array}$ & $\begin{array}{c}\text { Cut off } \\
\text { point }\end{array}$ & Sensitivity & Specificity \\
\hline Neuroticism & $\begin{array}{c}0.837 \\
(0.837-0.851)^{*}\end{array}$ & 5.21 & $77 \%$ & $66 \%$ & $\begin{array}{c}0.861 \\
(0.847-0.876)^{*}\end{array}$ & 5.22 & $81 \%$ & $77 \%$ & $\begin{array}{c}0.833 \\
(0.820-0.846)\end{array}$ & 5.20 & $77 \%$ & $74 \%$ \\
\hline Extraversion & $\begin{array}{c}0.799 \\
(0.763-0.794)^{*}\end{array}$ & 5.27 & $71 \%$ & $71 \%$ & $\begin{array}{c}0.737 \\
(0.717-0.756)^{*}\end{array}$ & 5.26 & $72 \%$ & $63 \%$ & $\begin{array}{c}0.756 \\
(0.771-0.740)\end{array}$ & 5.27 & $73 \%$ & $65 \%$ \\
\hline Openness & $\begin{array}{c}0.549 \\
(0.529-0.569)^{*}\end{array}$ & 5.22 & $68 \%$ & $41 \%$ & $\begin{array}{c}0.536 \\
(0.512-0.560)^{* *}\end{array}$ & 5.22 & $67 \%$ & $40 \%$ & $\begin{array}{c}0.564 \\
(0.582-0.545)\end{array}$ & 5.23 & $61 \%$ & $50 \%$ \\
\hline Agreeableness & $\begin{array}{c}0.677 \\
(0.658-0.695)^{*}\end{array}$ & 5.29 & $70 \%$ & $53 \%$ & $\begin{array}{c}0.667 \\
(645.0-689.0)\end{array}$ & 5.29 & $68 \%$ & $66 \%$ & $\begin{array}{c}0.659 \\
(0.676-0.642))\end{array}$ & 5.30 & $65 \%$ & $60 \%$ \\
\hline Conscientiousness & $\begin{array}{c}0.653 \\
(0.634-0.672)^{*}\end{array}$ & 5.34 & $72 \%$ & $54 \%$ & $\begin{array}{c}0.634 \\
(0.610-0.658)^{\star}\end{array}$ & 5.34 & $69 \%$ & $53 \%$ & $\begin{array}{c}0.654 \\
(0.662-0.627)\end{array}$ & 5.35 & $66 \%$ & $54 \%$ \\
\hline Total scores & $\begin{array}{c}0.547 \\
(0.527-0.567)^{\star}\end{array}$ & 137 & $70 \%$ & $40 \%$ & $\begin{array}{c}0.487 \\
(0.462-0.513)\end{array}$ & 140 & $68 \%$ & $44 \%$ & $\begin{array}{c}0.539 \\
(0.520-0.557)^{*}\end{array}$ & 137 & $70 \%$ & $38 \%$ \\
\hline
\end{tabular}

${ }^{\star} \mathrm{P}<.001 ;{ }^{* *} \mathrm{P}<.05$.

simultaneously based on multivariable logistic regression (Table 6) for each Psychological problem showed that it was a poor significant predictor for stress and depression but it was not significant for anxiety (Table 3) (Fig. 2).

Table 4 shows the area under the curve (95\% confidence interval), the cut-off point, the specificity, and the sensitivity of personality traits for predicting each Psychological problem in both genders. The area under the curve for the neuroticism in men and women was a significant indicator for the risk of being affected with stress, anxiety, and depression $(\mathrm{p}<.001)$ and other personality traits were identified as significant indices for the being unaffected with psychological problems $(\mathrm{p}<.001)$.

Using the ROC curve, the cut-off points were determined based on the best balance between sensitivity and specificity which the results were given in Table 5. Table 5 illustrates the area under the curve (95\% confidence interval), the cut-off point, the specificity, and the sensitivity of personality traits for predicting each studied Psychological problem in age groups above and under 40 years old. The area under the curve for the neuroticism in both age groups was a significant indicator for being affected with psychological problems $(\mathrm{p}<.001)$ while, other personality traits were significant indicators for lack of Psychological problems $(\mathrm{p}<.001)$.

Table 6 presents the results of univariate and multivariable logistic regression for the association of personality traits with each psychological problem. As can be seen, there are significant associations between all personality traits (neuroticism positively and other traits negatively are in relation with studied psychological problems) with psychological problem, however in multivariable analyses the associations are not significant for majority of personality traits.

\section{DISCUSSION}

In the present study, the prevalence of the most important common psychological problems in total sample and in age and gender groups was reported; also the prognostic value of each dimension of personality traits for these psychological problems in a large sample of Iranian adult population was investigated.

The most prevalent psychological problem in our study sample was depression in line with the results of previous studies in Iran [22] and across the world [23-26]. Comparing the results of the present study with the findings of other investigations in Iran and the world showed higher rates of psychological problems due to the use of different methods, instruments, and categorizations. Taking into account individuals with borderline scores as patients was another reason for estimating the higher prevalence of psychological problems in our study.

The prevalence of all three psychological problems in females was significantly higher than males. In most studies worldwide, the same results were obtained regardless of the country under study [5,22,27-30]. In this regard, numerous reasons have been highlighted for such a difference including sexual hormones and aspects of social roles [31-33]. There was no significant relationship between age and being affected with depression, while the prevalence of stress and anxiety higher among younger people. Consistent with the present study, several other investigations also showed the higher prevalence of psychological problems in younger age groups [25,34-36]. Some other studies showed that the prevalence of psychological problems increased with age $[5,22,37]$ while no significant difference was found in some other studies $[27,38]$.

In current study, individuals with depression, anxiety and stress had significantly higher neuroticism scores than non-affected group. The results were in agreement with the findings of previous literatures. As an example, in a meta-analysis study, high scores of neuroticism were obtained in anxious and depressed participants [11]. In a study by Birch; it was shown that the scores of stress, anxiety, and depression were significantly correlated with neuroticism scores [14]. Also, another study on the association of anxiety and personality traits showed significant correlation [39]. Another study by Robinson and others in 2009 similarly revealed that high levels of neuroticism were associated with depression [40]. In a study by Volgsten et al. (2010), women and men with depression and anxiety gained higher neuroticism scores compared to healthy 


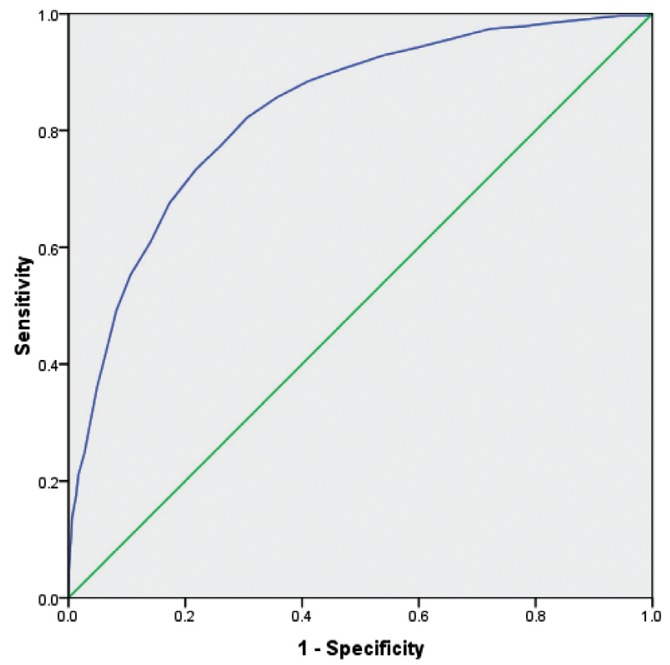

a) Area under the curve for predicting depression by neuroticism

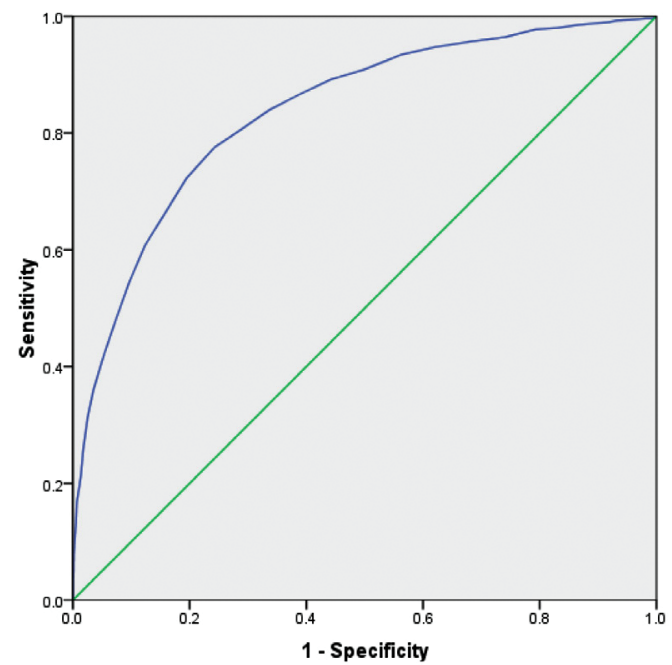

c) Area under the curve for predicting stress by neuroticism

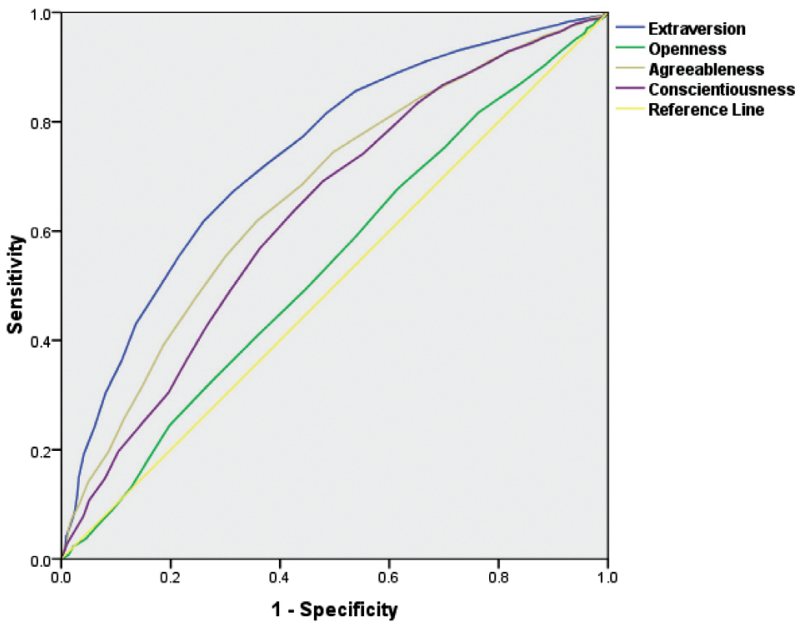

e) Area under the curve for predicting anxiety by other personality traits

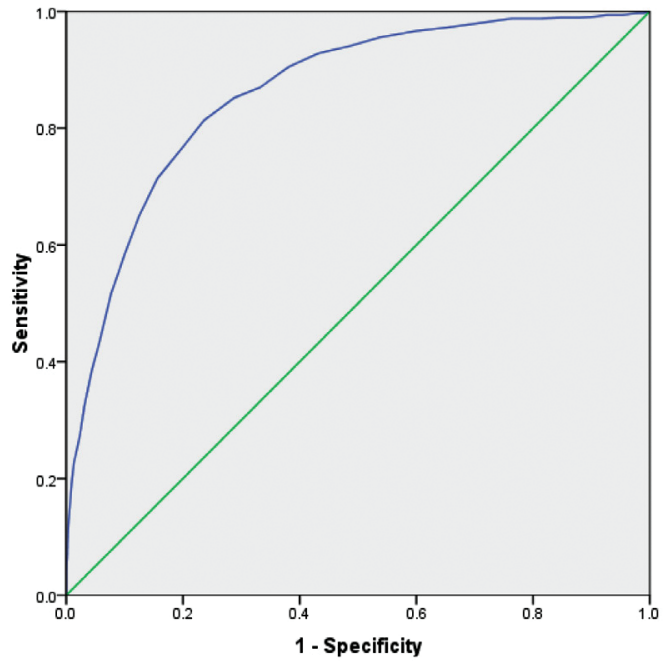

b) Area under the curve for predicting anxiety by neuroticism

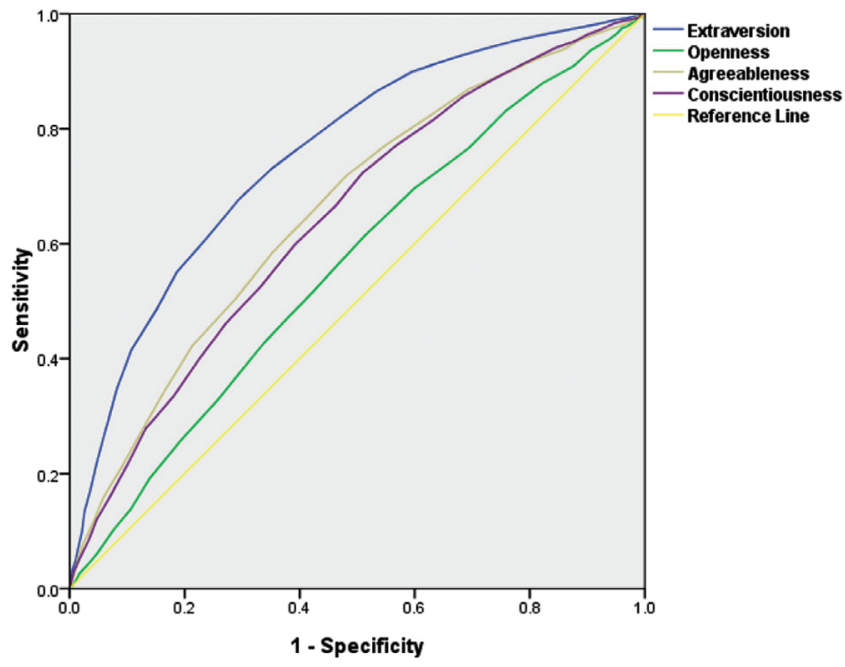

d) Area under the curve for predicting depression by other personality traits

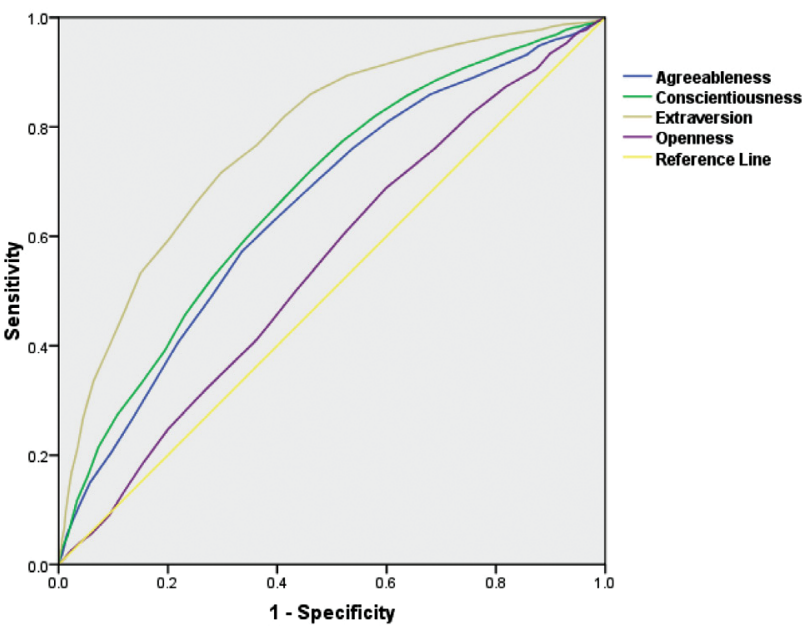

f) Area under the curve for predicting stress by other personality traits

Figure 1 Receiver-operating characteristic curve depicting area under the curve of personality traits for predicting psychological problems in total population. (a) Area under the curve for predicting depression by neuroticism. (b) Area under the curve for predicting anxiety by neuroticism. (c) Area under the curve for predicting stress by neuroticism. (d) Area under the curve for predicting depression by other personality traits. (e) Area under the curve for predicting anxiety by other personality traits. (f) Area under the curve for predicting stress by other personality traits 


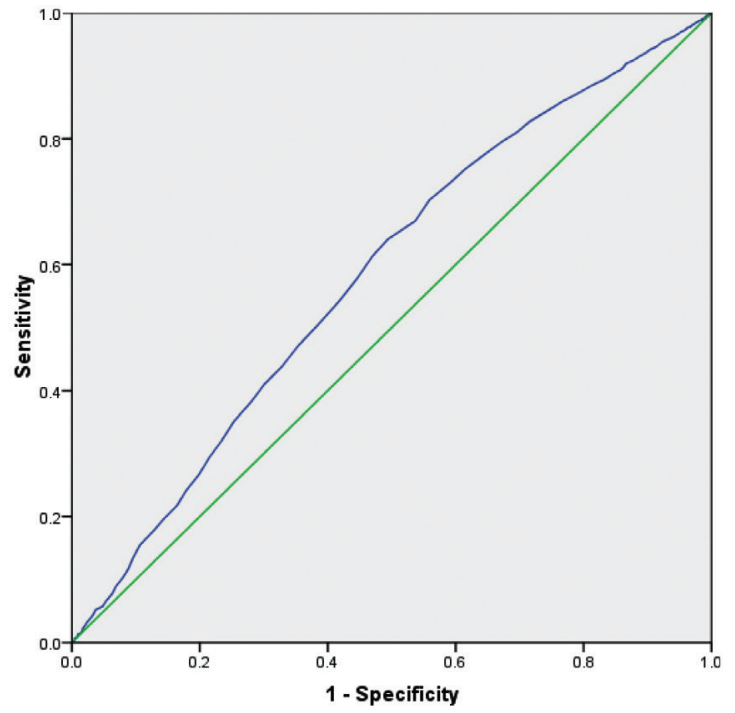

a) Area under the curve for predicting depression by sum of scores of all personality traits

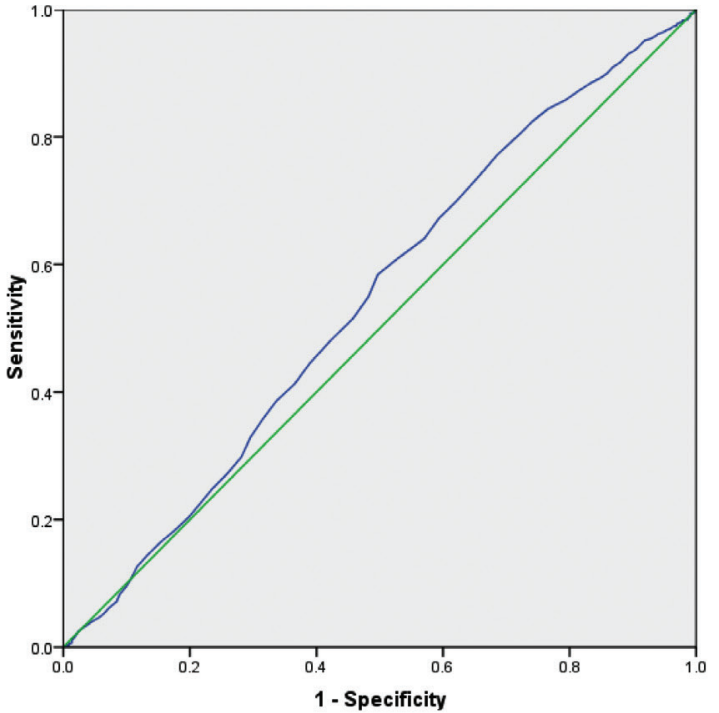

b) Area under the curve for predicting anxiety by sum of scores of all personality traits

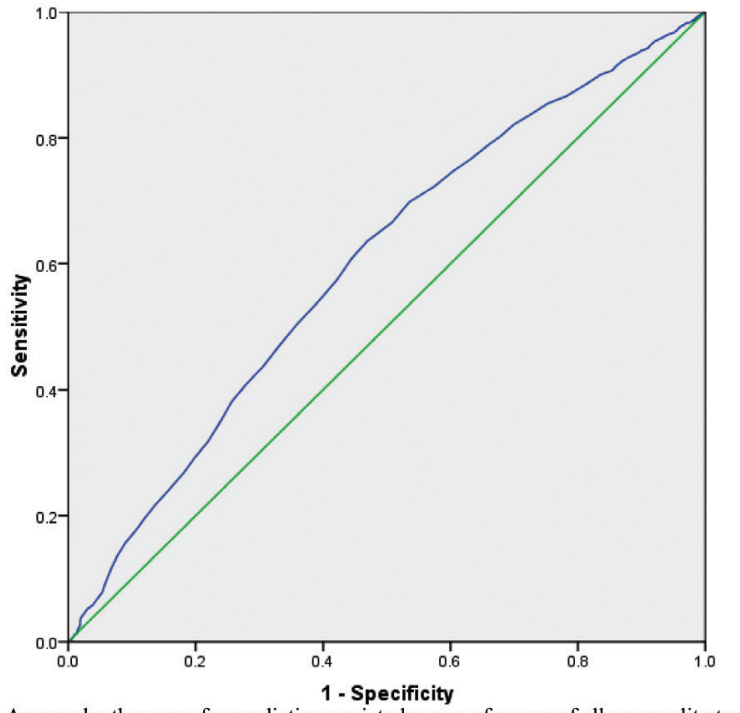

c) Area under the curve for predicting anxiety by sum of scores of all personality traits

Figure 2 Receiver-operating characteristic curve depicting area under the curve of sum of the scores of all personality traits simultaneously for predicting psychological disorders. (a) Area under the curve for predicting depression by sum of scores of all personality traits. (b) Area under the curve for predicting anxiety by sum of scores of all personality traits. (c) Area under the curve for predicting anxiety by sum of scores of all personality traits

individuals [41] and these findings are consistent with previous researches $[42,43]$. Klien in a study also found a significant relationship between neuroticism and depression [16]. Enns and Chioqueta in separate studies also showed that neuroticism was a predictor of depression $[44,45]$ and it was confirmed that neuroticism had a significant and positive correlation with anxiety and depression [46]. In a study by Bienvenu which aimed at investigating anxiety and depression as well as personality traits, a relationship was found between higher neuroticism scores and these disorders [47]. Likewise, Jakšić and others in a comprehensive systematic review concluded that the negative personality traits such as negative emotionality, neuroticism, hard avoidance etc. was positively correlated with stress [10].

In the present study, the mean scores of four other personality traits in affected individuals were lower than non-affected groups.
Previous studies have also shown conflicting results. Karsten's study in 2012 found a relationship between anxiety and depression and a decline in extraversion and conscientiousness [48]. In Chioqueta's study, extraversion was assumed as a negative predictor for depression [44]; furthermore, in a study by Magdalena and others, extraversion and openness as well as high degrees of agreeableness and conscientiousness were associated with a lower risk of depression [49] which was in line with the results of the present study. However; in a meta-analysis study, anxiety and depression were negatively associated with Conscientiousness which was consistent with the results of the present study but Agreeableness and Openness were unrelated with these disorders [11]. Spinhoven and others showed a negative correlation between depression and Extraversion; they also concluded that Conscientiousness was inversely associated with depression but it had a positive relationship with anxiety and anxious and depressed patients obtained 
Table 4 Areas under the receiver operating characteristics curves (AUC) and their 95\% confidence interval (CI), cutoff points, sensitivities and specificities of personality traits for psychological disorders by gender

\begin{tabular}{|c|c|c|c|c|c|c|c|c|c|c|c|c|}
\hline \multirow{2}{*}{$\begin{array}{l}\text { Personality } \\
\text { traits }\end{array}$} & \multicolumn{4}{|c|}{ Stress } & \multicolumn{4}{|c|}{ Anxiety } & \multicolumn{4}{|c|}{ Depression } \\
\hline & $\begin{array}{c}\text { AUC } \\
(95 \% \mathrm{CI})\end{array}$ & $\begin{array}{c}\text { Cutoff } \\
\text { point }\end{array}$ & Sensitivity & Specificity & $\begin{array}{c}\text { AUC } \\
(95 \% \mathrm{CI})\end{array}$ & $\begin{array}{l}\text { Cutoff } \\
\text { point }\end{array}$ & Sensitivity & Specificity & $\begin{array}{c}\text { AUC } \\
(95 \% \text { CI })\end{array}$ & $\begin{array}{c}\text { Cutoff } \\
\text { point }\end{array}$ & Sensitivity & Specificity \\
\hline \multicolumn{13}{|l|}{ Neuroticism } \\
\hline Men & $\begin{array}{c}0.826 \\
(0.804-0.851)^{*}\end{array}$ & 5.21 & $74 \%$ & $79 \%$ & $\begin{array}{c}0.864 \\
(0.838-0.890)^{*}\end{array}$ & 5.22 & $78 \%$ & $80 \%$ & $\begin{array}{c}0.833 \\
(0.821-0.851)^{*}\end{array}$ & 5.20 & $75 \%$ & $77 \%$ \\
\hline Women & $\begin{array}{c}0.839 \\
(0.821-0.856)^{\star}\end{array}$ & 5.22 & $74 \%$ & $79 \%$ & $\begin{array}{c}0.854 \\
(0.836-0.873)^{\star}\end{array}$ & 5.23 & $78 \%$ & $78 \%$ & $\begin{array}{c}0.828 \\
(0.812-0.845)^{\star}\end{array}$ & 5.21 & $74 \%$ & $77 \%$ \\
\hline \multicolumn{13}{|l|}{ Extraversion } \\
\hline Men & $\begin{array}{c}0.789 \\
(0.764-0.814)^{*}\end{array}$ & 5.28 & $71 \%$ & $72 \%$ & $\begin{array}{c}0.743 \\
(0.707-0.779)^{*}\end{array}$ & 5.26 & $72 \%$ & $67 \%$ & $\begin{array}{c}0.765 \\
(0.740-0.790)^{*}\end{array}$ & 5.28 & $72 \%$ & $68 \%$ \\
\hline Women & $\begin{array}{c}0.766 \\
(0.746-0.787)^{\star}\end{array}$ & 5.26 & $72 \%$ & $67 \%$ & $\begin{array}{c}0.724 \\
(0.699-0.750)^{*}\end{array}$ & 5.25 & $73 \%$ & $58 \%$ & $\begin{array}{c}0.741 \\
(0.721-0.761)^{\star}\end{array}$ & 5.26 & $73 \%$ & $61 \%$ \\
\hline \multicolumn{13}{|c|}{ Agreeableness } \\
\hline Men & $\begin{array}{c}0.565 \\
(0.531-0.598)^{*}\end{array}$ & 5.22 & $67 \%$ & $46 \%$ & $\begin{array}{c}0.535 \\
(0.492-0.578)^{\star}\end{array}$ & 5.21 & $74 \%$ & $31 \%$ & $\begin{array}{c}0.570 \\
(0.540-0.599)^{\star}\end{array}$ & 5.22 & $67 \%$ & $44 \%$ \\
\hline Women & $\begin{array}{c}0.547 \\
(0.522-0.572)^{\star}\end{array}$ & 5.22 & $70 \%$ & $38 \%$ & $\begin{array}{c}0.544 \\
(0.515-0.573)^{\star *}\end{array}$ & 5.22 & $69 \%$ & $38 \%$ & $\begin{array}{c}0.570 \\
(0.547-0.593)^{\star}\end{array}$ & 5.22 & $71 \%$ & $39 \%$ \\
\hline \multicolumn{13}{|l|}{ Openness } \\
\hline Men & $\begin{array}{c}0.686 \\
(0.654-0.716)^{\star}\end{array}$ & 5.30 & $73 \%$ & $54 \%$ & $\begin{array}{c}0.700 \\
(0.662-0.738)^{\star}\end{array}$ & 5.28 & $71 \%$ & $59 \%$ & $\begin{array}{c}0.691 \\
(0.664-0.719)^{\star}\end{array}$ & 5.29 & $67 \%$ & $61 \%$ \\
\hline Women & $\begin{array}{c}0.650 \\
(0.627-0.674)^{\star}\end{array}$ & 5.28 & $67 \%$ & $56 \%$ & $\begin{array}{c}0.668 \\
(0.642-0.695)^{*}\end{array}$ & 5.29 & $72 \%$ & $53 \%$ & $\begin{array}{c}0.570 \\
(0.638-0.660)^{\star}\end{array}$ & 5.30 & $69 \%$ & $55 \%$ \\
\hline \multicolumn{13}{|c|}{ Conscientiousness } \\
\hline Men & $\begin{array}{c}0.706 \\
(0.677-0.735)^{\star}\end{array}$ & 5.34 & $70 \%$ & $58 \%$ & $\begin{array}{c}0.662 \\
(0.619-0.704)^{*}\end{array}$ & 5.33 & $74 \%$ & $52 \%$ & $\begin{array}{c}0.677 \\
(0.694-0.706)^{*}\end{array}$ & 5.34 & $71 \%$ & $54 \%$ \\
\hline Women & $\begin{array}{c}0.664 \\
(0.541-0.688)^{\star}\end{array}$ & 5.34 & & & $\begin{array}{c}0.624 \\
(0.596-0.653)^{\star}\end{array}$ & 5.34 & $69 \%$ & $50 \%$ & $\begin{array}{c}0.631 \\
(0.609-0.654)^{*}\end{array}$ & 5.34 & $73 \%$ & $47 \%$ \\
\hline
\end{tabular}

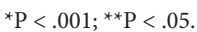

lower scores for Extraversion and Conscientiousness [50]. In this regard, some studies revealed that high Openness was associated with depression $[44,47,51]$. Several studies also showed a negative relationship between extroversion and depression $[45,47,52-$ 54]. On the relationship between personality traits and anxiety, Vreeke found an inverse relationship between Extraversion and Conscientiousness as well as Conscientiousness and anxiety [55]. In a study entitled "The role of personality traits on stress", it was assumed that Extraversion and Conscientiousness were negatively correlated with this disorder [10].

In line with previous studies, in our study higher levels of neuroticism were reported in women compared with men [56-60]. The present study showed that the mean score of Conscientiousness was higher in women than man that it was consistent with the obtained results in 55 countries regarding to the gender differences based on personality traits [60]. The Openness scores in current study were higher in women that were in line with the results of the study by Costa [56]; while Lehman et al. showed a higher rate of Openness in men [58]. Similar as other studies, in present study we observed higher scores of Agreeableness in women than men [56-60]. The present study demonstrated that Extraversion scores in men were higher than in women, while previous studies showed conflicting results in this regard [58-60]. Different social roles, pregnancy, hormonal effects, and also differences in sex-linked genetic endowments and different lifetime problems encountered by men and women could be considered as main reasons for gender differences in personality modes $[57,58]$.
Likewise, individuals who were under 40 years of age had higher scores in all five personality traits. Previous studies also showed higher scores of Neuroticism in younger individuals [58,61-63]. Like the results of present study, most of previous studies showed lower levels of conscientiousness along with increasing in age $[35,39,42,43,63]$.

In the present study, Openness was also higher in individuals aged below 40 years which was in agreement with the results of other studies $[35,39,43,64]$. In the study by Smits and others, a clear pattern was not observed about the scores of Openness in different age groups [64]. Mõttus and others [65] also found a negative relationship between Agreeableness and age which was consistent with the result of the present study, but other studies found a positive correlation between Agreeableness and age $[35,39,43,45]$. Majority of previous studies revealed that increased age could lead to a decline in the levels of extraversion in individuals $[39,43,60]$ also the results of Smits's study also revealed a small linear increasing trend between these two variables [64]; however, our study did not show significant difference between two age groups in terms of Extraversion scores. It should be noted that there are two views regarding to explain the relationship between age and personality traits; "the inherent view" and "the field-oriented" view which are focused on genetic factors and environmental factors, respectively. These two theories currently have been combined in a unified framework (person-environment interaction model) but there is still 
Table 5 Areas under the receiver operating characteristics curves (AUC) and their 95\% confidence interval (CI), cutoff points, sensitivities and specificities of personality traits for psychological disorders by age group

\begin{tabular}{|c|c|c|c|c|c|c|c|c|c|c|c|c|}
\hline \multirow{2}{*}{$\begin{array}{l}\text { Personality } \\
\text { traits }\end{array}$} & \multicolumn{4}{|c|}{ Stress } & \multicolumn{4}{|c|}{ Anxiety } & \multicolumn{4}{|c|}{ Depression } \\
\hline & $\begin{array}{c}\text { AUC } \\
(95 \% \mathrm{CI})\end{array}$ & $\begin{array}{c}\text { Cutoff } \\
\text { point }\end{array}$ & Sensitivity & Specificity & $\begin{array}{c}\text { AUC } \\
(95 \% \text { CI })\end{array}$ & $\begin{array}{c}\text { Cutoff } \\
\text { point }\end{array}$ & Sensitivity & Specificity & $\begin{array}{c}\text { AUC } \\
(95 \% \mathrm{CI})\end{array}$ & $\begin{array}{l}\text { Cutoff } \\
\text { point }\end{array}$ & Sensitivity & Specificity \\
\hline \multicolumn{13}{|l|}{ Neuroticism } \\
\hline$\leq 40$ & $\begin{array}{c}0.856 \\
(0.840-0.872)^{*}\end{array}$ & 5.22 & $76 \%$ & $80 \%$ & $\begin{array}{c}0.870 \\
(0.853-0.877)^{\star}\end{array}$ & 5.23 & $79 \%$ & $79 \%$ & $\begin{array}{c}0.843 \\
(0.827-0.859)^{*}\end{array}$ & 5.21 & $76 \%$ & $77 \%$ \\
\hline$>40$ & $\begin{array}{c}0.800 \\
(0.773-0.827)^{\star}\end{array}$ & 5.20 & $73 \%$ & $73 \%$ & $\begin{array}{c}0.843 \\
(0.815-0.871)^{\star}\end{array}$ & 5.22 & $76 \%$ & $79 \%$ & $\begin{array}{c}0.813 \\
(0.796-0.840)^{*}\end{array}$ & 5.20 & $72 \%$ & $77 \%$ \\
\hline \multicolumn{13}{|l|}{ Extraversion } \\
\hline$\leq 40$ & $\begin{array}{c}0.794 \\
(0.813-0.775)^{\star}\end{array}$ & 5.27 & $72 \%$ & $72 \%$ & $\begin{array}{c}0.794 \\
(0.724-0.744)^{\star}\end{array}$ & 5.26 & $72 \%$ & $65 \%$ & $\begin{array}{c}0.763 \\
(0.744-0.782)^{\star}\end{array}$ & 5.27 & $72 \%$ & $67 \%$ \\
\hline$>40$ & $\begin{array}{c}0.753 \\
(0.726-0.781)^{\star}\end{array}$ & 5.27 & $71 \%$ & $68 \%$ & $\begin{array}{c}0.716 \\
(0.681-0.751)^{\star}\end{array}$ & 5.26 & $71 \%$ & $59 \%$ & $\begin{array}{c}0.744 \\
(0.718-0.769)^{*}\end{array}$ & 5.27 & $73 \%$ & $63 \%$ \\
\hline \multicolumn{13}{|c|}{ Agreeableness } \\
\hline$\leq 40$ & $\begin{array}{c}0.538 \\
(0.513-0.563)^{\star *}\end{array}$ & 5.22 & $71 \%$ & $38 \%$ & $\begin{array}{c}0.538 \\
(0.497-0.578)^{\star *}\end{array}$ & 5.23 & $61 \%$ & $45 \%$ & $\begin{array}{c}0.561 \\
(0.538-0.585)^{*}\end{array}$ & 5.23 & $63 \%$ & $47 \%$ \\
\hline$>40$ & $\begin{array}{c}0.575 \\
(0.542-609)^{\star}\end{array}$ & 5.22 & $65 \%$ & $46 \%$ & $\begin{array}{c}0.570 \\
(0.541-0.600)^{*}\end{array}$ & 5.22 & $63 \%$ & $40 \%$ & $\begin{array}{c}0.570 \\
(0.541-0.600)^{*}\end{array}$ & 22.5 & $65 \%$ & $44 \%$ \\
\hline \multicolumn{13}{|l|}{ Openness } \\
\hline$\leq 40$ & $\begin{array}{c}0.664 \\
(0.641-0.687)^{\star}\end{array}$ & 5.29 & $72 \%$ & $51 \%$ & $\begin{array}{c}0.654 \\
(0.628-0.681)^{\star}\end{array}$ & 5.30 & $63 \%$ & $61 \%$ & $\begin{array}{c}0.666 \\
(0.644-0.687)^{*}\end{array}$ & 5.29 & $73 \%$ & $50 \%$ \\
\hline$>40$ & $\begin{array}{c}0.640 \\
(0.607-0.672)^{*}\end{array}$ & 5.29 & $68 \%$ & $66 \%$ & $\begin{array}{c}0.699 \\
(0.661-0.736)^{*}\end{array}$ & 5.28 & $73 \%$ & $60 \%$ & $\begin{array}{c}0.651 \\
(0.622-0.679)^{*}\end{array}$ & 5.29 & $70 \%$ & $66 \%$ \\
\hline \multicolumn{13}{|c|}{ Conscientiousness } \\
\hline$\leq 40$ & $\begin{array}{c}0.688 \\
(0.665-0.710)^{*}\end{array}$ & 5.34 & $73 \%$ & $55 \%$ & $\begin{array}{c}0.642 \\
(0.612-0.671)^{\star}\end{array}$ & 5.34 & $70 \%$ & $54 \%$ & $\begin{array}{c}0.652 \\
(0.630-0.674)^{*}\end{array}$ & 5.34 & $73 \%$ & $50 \%$ \\
\hline$>40$ & $\begin{array}{c}0.660 \\
(0.629-0.691)^{\star}\end{array}$ & 5.34 & $69 \%$ & $52 \%$ & $\begin{array}{c}0.621 \\
(0.581-0.661)^{\star}\end{array}$ & 5.33 & $73 \%$ & $41 \%$ & $\begin{array}{c}0.633 \\
(0.605-0.662)^{*}\end{array}$ & 5.34 & $71 \%$ & $48 \%$ \\
\hline
\end{tabular}

${ }^{*} \mathrm{P}<.001 ;{ }^{* * \mathrm{P}}<.05$.

Table 6 Odds ratio (OR) and 95\% confidence interval (95\% CI) for the association of personality traits with psychological problems

\begin{tabular}{|c|c|c|c|c|c|c|}
\hline \multirow{3}{*}{ Personality traits } & \multicolumn{6}{|c|}{ Psychological problems } \\
\hline & \multicolumn{3}{|c|}{ Depression } & \multicolumn{2}{|c|}{ Anxiety } & \multirow{2}{*}{$\begin{array}{c}\text { Stress } \\
\text { Multivariable }\end{array}$} \\
\hline & Univariate & Multivariable & Univariate & Multivariable & Univariate & \\
\hline Neuroticism & $1.23(1.21-1.25)^{*}$ & $1.19(1.17-1.21)^{*}$ & $1.24(1.22-1.28)^{*}$ & $1.23(1.20-1.26)^{*}$ & $1.23(1.21-1.26)^{*}$ & $1.20(1.18-1.22)^{*}$ \\
\hline Extraversion & $0.85(0.84-0.87)^{*}$ & $0.89(0.88-0.93)^{*}$ & $0.89(0.88-0.90)^{*}$ & $0.96(0.94-0.99)^{*}$ & $0.85(0.83-0.86)^{*}$ & $0.90(0.88-0.92)^{*}$ \\
\hline Openness & $0.97(0.96-0.99)^{*}$ & $1.02(0.99-1.05)$ & $0.98(0.96-1.00)$ & $0.99(0.97-1.03)$ & $0.97(0.96-0.99)^{*}$ & $1.01(0.99-1.04)$ \\
\hline Agreeableness & $0.91(0.89-0.92)^{*}$ & $1.01(0.99-1.04)$ & $0.91(0.90-0.93)^{*}$ & $0.97(0.95-1.01)$ & $0.92(0.90-0.93)^{*}$ & $0.99(0.97-1.01)$ \\
\hline Conscientiousness & $0.93(0.92-0.94)^{*}$ & $0.97(0.95-0.99)^{*}$ & $0.94(0.92-0.95)^{*}$ & $1.02(0.99-1.05)$ & $0.91(0.90-0.93)^{*}$ & $1.02(0.99-1.04)$ \\
\hline
\end{tabular}

controversy over the issue that which factor is stronger (genetics or environment) [66].

\section{CONCLUSION}

The present study compared to other investigations is the first one that using ROC curve analysis the prognostic values of various personality dimensions was evaluated for being affected with common psychological problems. The present study showed that the higher scores of neuroticism were positive predictor for suffering from three common metal disorders while other four personality traits were significant predictors of being unaffected with metal problems. These results were observed in total sample as well as separately in men and women. Although, we have observed significant predictive role of each personality traits for three studied psychological problems in univariate analysis, their associations in multivariable analysis were not statistically significant. When all five domains of personality were entered into statistical model, they attenuated their impacts on metal problems, resulting non-significant associations.

\section{CONFLICT OF INTEREST}

All authors declare that they have no conflict of interests.

\section{ACKNOWLEDGEMENTS}

The present article was extracted from an MSc thesis at the School of Health, Isfahan University of Medical Sciences, in the framework 
of SEPAHN study. SEPAHAN was financially supported by a grant from the Vice Chancellery for Research and Technology, Isfahan University of Medical Sciences (IUMS). We are grateful to thank all staff of Isfahan University of Medical Sciences (MUI) who kindly participated in our study and staff of Public Relations Unit, and other authorities of IUMS for their excellent cooperation.

\section{REFERENCES}

[1] Stein DJ, Phillips KA, Bolton D, Fulford K, Sadler JZ, Kendler KS. What is a mental/psychiatric disorder? From DSM-IV to DSM-V. Psychol Med 2010;40;1759-65.

[2] Kessler R, Aguilar-Gaxiola S, Alonso J, Chatterji S, Lee S, Ormel J, et al. The global burden of mental disorders: an update from the WHO World Mental Health (WMH) surveys. Epidemiol Psychiatr Sci 2009;18;23.

[3] Kessler RC, Berglund P, Demler O, Jin R, Merikangas KR, Walters EE. Lifetime prevalence and age-of-onset distributions of DSM-IV disorders in the national comorbidity survey replication. Arch Gen Psychiatry 2005;62;593-602.

[4] Wittchen H-U, Jacobi F, Rehm J, Gustavsson A, Svensson $\mathrm{M}$, Jönsson $\mathrm{B}$, et al. The size and burden of mental disorders and other disorders of the brain in Europe 2010. Eur Neuropsychopharmacol 2011;21;655-79.

[5] Mohammadi M-R, Davidian H, Noorbala AA, Malekafzali H, Naghavi HR, Pouretemad HR, et al. An epidemiological survey of psychiatric disorders in Iran. Clin Pract Epidemiol Ment Health 2005; $1 ; 16$.

[6] Lokkerbol J, Adema D, de Graaf R, Ten Have M, Cuijpers P, Beekman A, et al. Non-fatal burden of disease due to mental disorders in the Netherlands. Soc Psychiatry Psychiatr Epidemiol 2013;48;1-9.

[7] Begg SJ, Vos T, Barker B, Stanley L, Lopez AD. Burden of disease and injury in Australia in the new millennium: measuring health loss from diseases, injuries and risk factors. Aust Med J 2008; 188;36-40.

[8] Spinhoven P, Elzinga B, Hovens J, Roelofs K, van Oppen P, Zitman F, et al. Positive and negative life events and personality traits in predicting course of depression and anxiety. Acta Psychiatr Scand 2011;124;462-73.

[9] Grossarth-Maticek R, Bastiaans J, Kanazir DT. Psychosocial factors as strong predictors of mortality from cancer, ischaemic heart disease and stroke: the Yugoslav prospective study. J Psychosom Res 1985;29;167-76.

[10] Jakšić N, Brajković L, Ivezić E, Topić R, Jakovljević M. The role of personality traits in posttraumatic stress disorder (PTSD). Psychiatr Danub 2012;24;256-66.

[11] Kotov R, Gamez W, Schmidt F, Watson D. Linking, "big” personality traits to anxiety, depressive, and substance use disorders: a meta-analysis. Psychol Bull 2010;136;768-821.

[12] Clark LA, Watson D, Mineka S. Temperament, personality, and the mood and anxiety disorders. J Abnorm Psychol 1994;103;103-16.

[13] Mulder RT. Personality pathology and treatment outcome in major depression: a review. Am J Psychiatry 2002;159;359-71.

[14] Newbury-Birch D, Kamali F. Psychological stress, anxiety, depression, job satisfaction, and personality characteristics in preregistration house officers. Postgrad Med J 2001;77;109-11.

[15] Costa PT, McCrae RR. Normal personality assessment in clinical practice: the NEO personality inventory. Psychol Assess $1992 ; 4 ; 5-13$.
[16] Klein DN, Kotov R, Bufferd SJ. Personality and depression: explanatory models and review of the evidence. Annu Rev Clin Psychol 2011;7;269-95.

[17] Adibi P, Keshteli AH, Esmaillzadeh A, Afshar H, Roohafza H, Bagherian-Sararoudi R, et al. The study on the epidemiology of psychological, alimentary health and nutrition (SEPAHAN): overview of methodology. J Res Med Sci 2012;17;291-7.

[18] Costa Jr PT, McCrae RR. Stability and change in personality assessment: the revised NEO Personality Inventory in the year 2000. J Pers Assess 1997;68;86-94.

[19] Atari Y, Aman Elahifard A. An investigation of relationships between personality characteristics and family-personal factors and marital satisfaction in administrative office personnel in Ahvaz. J Educ Psychol 2006;13;81-108.

[20] Montazeri A, Vahdaninia M, Ebrahimi M, Jarvandi S. The hospital anxiety and depression scale (HADS): translation and validation study of the Iranian version. Health Qual Life Outcomes 2003;1;1.

[21] Montazeri A, Harirchi AM, Shariati M, Garmaroudi G, Ebadi M, Fateh A. The 12-item General Health Questionnaire (GHQ-12): translation and validation study of the Iranian version. Health Qual Life Outcomes 2003;1;1.

[22] Noorbala A, Yazdi SB, Yasamy M, Mohammad K. Mental health survey of the adult population in Iran. Br J Psychiatry $2004 ; 184 ; 70-3$.

[23] Kringlen E, Torgersen S, Cramer V. A Norwegian psychiatric epidemiological study. Am J Psychiatry 2001;58:1091-8.

[24] Klose M, Jacobi F. Can gender differences in the prevalence of mental disorders be explained by sociodemographic factors? Arch Womens Ment Health 2004;7;133-48.

[25] Viana MC, Andrade LH. Lifetime prevalence, age and gender distribution and age-of-onset of psychiatric disorders in the São Paulo metropolitan area, Brazil: results from the São Paulo megacity mental health survey. Rev Bras Psiquiatr 2012;34;249-60.

[26] Wittchen H-U, Nelson CB, Lachner G. Prevalence of mental disorders and psychosocial impairments in adolescents and young adults. Psychol Med 1998;28;109-26.

[27] Barcelos-Ferreira R, Pinto Jr JA, Nakano EY, Steffens DC, Litvoc J, Bottino CM. Clinically significant depressive symptoms and associated factors in community elderly subjects from Sao Paulo, Brazil. Am J Geriatr Psychiatry 2009;17;582-90.

[28] Gove WR. Sex differences in mental illness among adult men and women: an evaluation of four questions raised regarding the evidence on the higher rates of women. Soc Sci Med B 1978;12;187-98.

[29] Afifi M. Gender differences in mental health. Singapore Med J 2007;48;385-91.

[30] Piccinelli M, Wilkinson G. Gender differences in depression critical review. Br J Psychiatry 2000;177;486-92.

[31] Gove WR. Gender differences in mental and physical illness: the effects of fixed roles and nurturant roles. Soc Sci Med 1984;19; 77-84.

[32] Kinrys G, Wygant LE. Anxiety disorders in women: does gender matter to treatment? Rev Bras Psiquiatr 2005;27;\$43-s50.

[33] Parker GB, Brotchie HL. From diathesis to dimorphism: the biology of gender differences in depression. J Nerv Ment Dis 2004;192;210-16.

[34] Andrade L, Berglund P, Bijl R, Kessler R, Demler O, Walters E, et al. Cross-national comparisons of the prevalences and correlates of mental disorders. Bull World Health Organ 2000;784.

[35] Scott K, Von Korff M, Alonso J, Angermeyer M, Bromet E, Bruffaerts R, et al. Age patterns in the prevalence of DSM-IV 
depressive/anxiety disorders with and without physical comorbidity. Psychol Med 2008;38;1659-69.

[36] Scott K, Von Korff M, Alonso J, Angermeyer M, Bromet E, Bruffaerts R, et al. Age patterns in the prevalence of DSM-IV depressive/anxiety disorders with and without physical comorbidity. Psychol Med 2008;38;1659-69.

[37] Glaesmer H, Riedel-Heller S, Braehler E, Spangenberg L, Luppa M. Age-and gender-specific prevalence and risk factors for depressive symptoms in the elderly: a population-based study. Int Psychogeriatr 2011;23;1294-300.

[38] Kessler RC, Birnbaum H, Bromet E, Hwang I, Sampson N, Shahly V. Age differences in major depression: results from the National Comorbidity Survey Replication (NCS-R). Psychol Med 2010;12;225-37.

[39] Sharma S. Generalized anxiety disorder and personality traits. Kathmandu Univ Med J (KUMJ) 2003;1;248-50.

[40] Robison EJ, Shankman SA, McFarland BR. Independent associations between personality traits and clinical characteristics of depression. J Nerv Ment Dis 2009;197;476-83.

[41] Volgsten H, Ekselius L, Poromaa IS, Svanberg AS. Personality traits associated with depressive and anxiety disorders in infertile women and men undergoing in vitro fertilization treatment. Acta Obstet Gynecol Scand 2010;89;27-34.

[42] Saklofske D, Kelly I, Janzen B. Neuroticism, depression, and depression proneness. Pers Individ Dif 1995;18;27-31.

[43] Xia J, He Q, Li Y, Xie D, Zhu S, Chen J, et al. The relationship between neuroticism, major depressive disorder and comorbid disorders in Chinese women. J Affect Disord 2011;135;100-5.

[44] Chioqueta AP, Stiles TC. Personality traits and the development of depression, hopelessness, and suicide ideation. Pers Individ Dif 2005;38;1283-91.

[45] Enns MW, Cox BJ. Personality dimensions and depression: review and commentary. Can J Psychiatry 1997;42;274-84.

[46] Rosellini AJ, Brown TA. The NEO five-factor inventory: latent structure and relationships with dimensions of anxiety and depressive disorders in a large clinical sample. Assessment 2011;18;27-38.

[47] Bienvenu OJ, Samuels JF, Costa PT, Reti IM, Eaton WW, Nestadt G. Anxiety and depressive disorders and the five-factor model of personality: a higher-and lower-order personality trait investigation in a community sample. Depress Anxiety 2004;20;92-7.

[48] Karsten J, Penninx BW, Riese H, Ormel J, Nolen WA, Hartman CA. The state effect of depressive and anxiety disorders on big five personality traits. J Psychiatr Res 2012;46;644-50.

[49] Podolska MZ, Bidzan M, Majkowicz M, Podolski J, Sipak-Szmigiel O, Ronin-Walknowska E. Personality traits assessed by the NEO Five-Factor Inventory (NEO-FFI) as part of the perinatal depression screening program. Med Sci Monit 2010;16;77-81.

[50] Spinhoven P, de Rooij M, Heiser W, Smit JH, Penninx BW. The role of personality in comorbidity among anxiety and depressive disorders in primary care and specialty care: a cross-sectional analysis. Gen Hosp Psychiatry 2009;31;470-7.

[51] Jain U, Blais MA, Otto MW, Hirshfeld DR, Sachs GS. Five-factor personality traits in patients with seasonal depression: treatment effects and comparisons with bipolar patients. J Affect Disord 1999;55;51-4.

[52] Spinhoven P, Elzinga B, Roelofs K, Hovens JG, van Oppen P, Zitman FG, et al. The effects of neuroticism, extraversion, and positive and negative life events on a one-year course of depressive symptoms in euthymic previously depressed patients versus healthy controls. J Nerv Ment Dis 2011;199;684-89.

[53] Jylhä P, Melartin T, Isometsä E. Relationships of neuroticism and extraversion with axis I and II comorbidity among patients with DSM-IV major depressive disorder. J Affect Disord 2009; $114 ; 110-21$.

[54] Freire RC, Lopes FL, Veras AB, Valença AM, Mezzasalma MA, Nascimento I, et al. Personality traits spectrum in panic disorder and major depression. Rev Bras Psiquiatr 2007;29;31-4.

[55] Vreeke LJ, Muris P. Relations between behavioral inhibition, big five personality factors, and anxiety disorder symptoms in non-clinical and clinically anxious children. Child Psychiatry Hum Dev 2012;43;884-94.

[56] Costa Jr P, Terracciano A, McCrae RR. Gender differences in personality traits across cultures: robust and surprising findings. J Pers Soc Psychol 2001;81;322-31.

[57] Chapman BP, Duberstein PR, Sörensen S, Lyness JM. Gender differences in five factor model personality traits in an elderly cohort. Pers Individ Dif 2007;43;1594-603.

[58] Lehmann R, Denissen JJ, Allemand M, Penke L. Age and gender differences in motivational manifestations of the big five from age 16 to 60. Dev Psychol 2013;49;365-83.

[59] Weisberg YJ, DeYoung CG, Hirsh JB. Gender differences in personality across the ten aspects of the big five. Front Psychol 2011;2;178.

[60] Schmitt DP, Realo A, Voracek M, Allik J. Why can't a man be more like a woman? Sex differences in Big Five personality traits across 55 cultures. J Pers Soc Psychol 2008;94;168.

[61] McCrae RR, Costa PT, de Lima MP, Simões A, Ostendorf F, Angleitner A, et al. Age differences in personality across the adult life span: parallels in five cultures. Dev Psychol 1999;35;466-77.

[62] Chan W, McCrae RR, De Fruyt F, Jussim L, Löckenhoff CE, De Bolle M, et al. Stereotypes of age differences in personality traits: universal and accurate?. J Pers Soc Psychol 2012;103:1050-66.

[63] Donnellan MB, Lucas RE. Age differences in the Big Five across the life span: evidence from two national samples. Psychol Aging 2008;23;558-66.

[64] Smits IA, Dolan CV, Vorst H, Wicherts JM, Timmerman ME. Cohort differences in Big Five personality factors over a period of 25 years. J Pers Soc Psychol 2011;100;1124-38.

[65] Mõttus R, Johnson W, Deary IJ. Personality traits in old age: measurement and rank-order stability and some mean-level change. Psychol Aging 2012;27;243-9.

[66] Specht J, Egloff B, Schmukle SC. Stability and change of personality across the life course: the impact of age and major life events on mean-level and rank-order stability of the Big Five. J Pers Soc Psychol 2011;101;862-82. 